\title{
Organic aerosol formation via sulphate cluster activation
}

\author{
Markku Kulmala, ${ }^{1}$ Veli-Matti Kerminen, ${ }^{2}$ Tatu Anttila, ${ }^{1,2}$ Ari Laaksonen, ${ }^{3}$ \\ and Colin D. O’Dowd ${ }^{4}$ \\ Received 8 July 2003; revised 18 November 2003; accepted 11 December 2003; published 25 February 2004.
}

[1] The formation of aerosols, and subsequent cloud condensation nuclei, remains one of the least understood atmospheric processes upon which global climate change critically depends. Under atmospheric conditions, the process of homogeneous nucleation (formation of stable clusters $\sim 1 \mathrm{~nm}$ in size), and their subsequent growth into new particles $(>3 \mathrm{~nm})$, determines the aerosol and cloud nuclei population, yet, hitherto, no theory has elucidated the new particle formation phenomenon in detail. In this study, we present a new theory which provides a mechanistic explanation for new particle formation via activation of stable inorganic clusters by organic vapors. The new nano-particle activation theory is analogous to Köhler theory which describes cloud formation in a supersaturated water vapor field but differs in that it describes the activation of inorganic stable nano-clusters into aerosol particles in a supersaturated organic vapor which initiates spontaneous and rapid growth of clusters. Inclusion of the new theory into aerosol formation models predicts that increases in organic vapor densities lead to even greater increases in particle production, which, in turn, will influence the global radiative cooling effect of atmospheric aerosols. INDEX TERMS: 0305 Atmospheric Composition and Structure: Aerosols and particles (0345, 4801); 0315 Atmospheric Composition and Structure: Biosphere/atmosphere interactions

Citation: Kulmala, M., V.-M. Kerminen, T. Anttila, A. Laaksonen, and C. D. O'Dowd (2004), Organic aerosol formation via sulphate cluster activation, J. Geophys. Res., 109, D04205, doi:10.1029/2003JD003961.

\section{Introduction}

[2] Atmospheric aerosol particles contribute directly to the global radiative balance through the direct backscatter of solar radiation by haze and cloud layers [Charlson et al., 1987, 1992; Houghton et al., 2001]; however, this system comprises the greatest uncertainty in terms of future climate change prediction [Houghton et al., 2001]. The concentration of aerosols is strongly influenced by new particle formation yet, the qualitative, and in particular, the quantitative understanding of atmospheric nucleation processes is far from complete [Seinfeld and Pandis, 1998].

[3] New particle formation is a two-stage process [Kulmala et al., 2000]: the first stage comprises homogeneous nucleation of thermodynamically stable clusters, while the second stage involves condensation and coagulation growth of the clusters into quasi-stable aerosol particles

\footnotetext{
${ }^{1}$ Department of Physical Sciences, University of Helsinki, Helsinki, Finland.

${ }^{2}$ Air Quality Research, Finnish Meteorological Institute, Sahaajankatu, Helsinki, Finland.

${ }^{3}$ Department of Applied Physics, University of Kuopio, Kuopio, Finland.

${ }^{4}$ Department of Experimental Physics and Environmental Change Institute, National University of Ireland, Galway, University Road, Galway, Ireland.
}

Copyright 2004 by the American Geophysical Union. 0148-0227/04/2003JD003961 (typically $\mathrm{d}>3 \mathrm{~nm}$ ). If the growth is not sufficiently fast, the clusters coagulate with, and are removed by, the preexisting aerosol population and no new particle formation results [Kulmala et al., 2000; O'Dowd et al., 2002a]. It is now generally accepted that, under tropospheric conditions, the most likely nucleating species are $\mathrm{H}_{2} \mathrm{SO}_{4}, \mathrm{H}_{2} \mathrm{O}$, and $\mathrm{NH}_{3}$, forming clusters of $\sim 1 \mathrm{~nm}$ in diameter [Kulmala et al., 2000] although it should be noted that very rarely is $\mathrm{H}_{2} \mathrm{SO}_{4}$ abundant enough to drive the growth of clusters into sizes larger than $2 \mathrm{~nm}$ and therefore they do not become detectable particles [Kulmala et al., 2000; O'Dowd et al., 2002b]. Furthermore, there are typically insufficient clusters produced to allow notable growth by coagulation [Kulmala et al., 2000]. Therefore the question remains: what process can drive the growth of clusters into stable aerosol particles?

[4] Recently conducted modeling studies suggest that condensation of organic low-volatile vapors play a key role in the growth of freshly-formed clusters and particles [e.g., Kerminen, 1999; Kerminen et al., 2000; Kulmala et al., 2001; Anttila and Kerminen, 2003]. Recent laboratory experiments also indicate that heterogeneous reactions might enhance uptake of organic vapors by particles [Tobias and Ziemann, 2000; Jang et al., 2002; Noziére and Riemer, 2003], while it is not known whether these reactions can influence particle growth under real atmospheric conditions. Zhang and Wexler [2002] have suggested that heterogeneous reactions may help nanometer-sized fresh atmospheric nuclei over the huge Kelvin barrier that would prevent condensation of pure organic vapors. Field measurements indicate that organic vapors are the dominant 


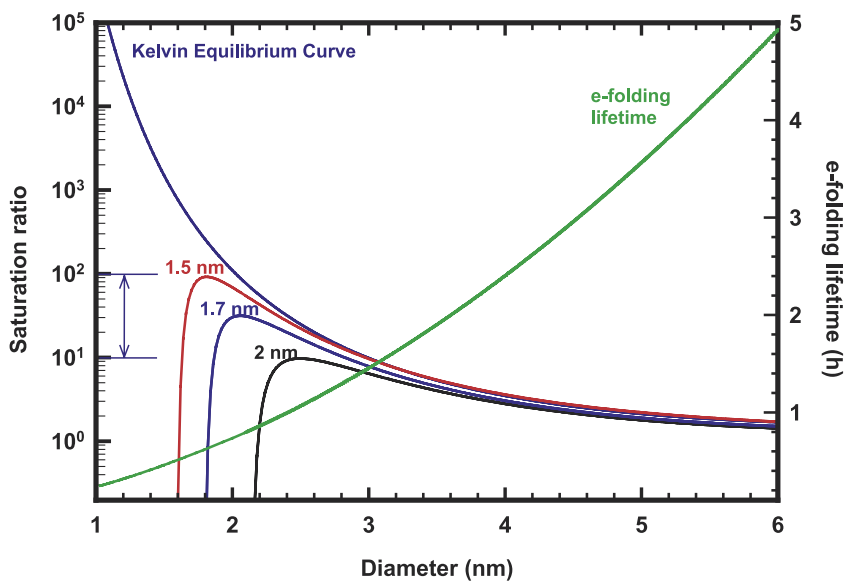

Figure 1. Comparison of Kelvin equilibrium curve for a pure organic droplet and nano-particle equilibrium curves for clusters with initial nuclei sizes of $1.5,1.7$ and $2 \mathrm{~nm}$. The range of saturation ratios expected for condensable organic vapors based on analytical estimates is highlighted. Also shown is the e-folding lifetime, i.e., the inverse of the coagulation sink, of nanometer-size particles.

contributors to nano-particle chemical composition [Marti et al., 1997; Kavouras et al., 1998; Leaitch et al., 1999; Kavouras and Stephanou, 2002; O'Dowd et al., 2002c], particularly in regions where biogenic volatile organic compound emissions are high. What is lacking, however, is a detailed theoretical framework that could be readily applied to explain and quantify the formation of organic nano-particles in the atmosphere. In particular, thermodynamic interactions between organic and inorganic compounds present in growing clusters and particles have been neglected so far.

[5] The present study aims to fill the above-discussed gap by presenting a novel theory that is analogous to Köhler theory which describes the formation of cloud droplets due to spontaneous condensation of water vapor. Our main goals are to show that significant aerosol formation may take place in the atmosphere via such a mechanism and that the theory developed improves the current understanding concerning the feedbacks between aerosols, clouds and climate.

\section{Nano-Köhler Theory}

[6] As discussed in the Introduction, there is convincing experimental evidence for the prevalence of condensed organic species in new 3-5 nm particles [O'Dowd et al., 2002c]. However, a theoretical explanation for this phenomenon is lacking since homogeneous nucleation of organic vapors under atmospheric conditions is not thermodynamically viable. Figure 1 illustrates the Kelvin equilibrium curve for a generic organic vapor with thermodynamic properties constrained to replicate observations (a detailed discussion of these properties is presented below). For homogeneous nucleation of a $1 \mathrm{~nm}$ organic cluster to occur, organic vapor saturation ratio in excess of $10^{4}-10^{5}$ are required. Previous analysis indicates that the vapor concentration is between $10^{7}$ and $3 \times 10^{8} \mathrm{~cm}^{-3}$ Kulmala et al., 2001] and the maximum saturation vapor pressure corresponds to a concentration of $\sim 10^{6} \mathrm{~cm}^{-3}$ [Kulmala et al., 1998; Kerminen et al., 2000; Anttila and Kerminen, 2003]. These estimates of the saturation vapor pressure for the organic vapor have been corroborated by very recent laboratory studies into organic vapor nucleation where a maximum value of $2.9 \times 10^{6} \mathrm{~cm}^{-3}$ was derived [Bonn and Moortgat, 2003]. Therefore the estimated saturation ratios in the atmosphere during nano-particle formation and growth events lie between unity and 100 which is well below that required for homogeneous nucleation. Obviously, lower saturation vapor pressures will lead to higher saturation ratios than those estimated here.

[7] To further elucidate the role of organic compounds in atmospheric particle formation, we have developed a new theoretical framework which provides a mechanistic explanation behind organic new particle formation. This theory is analogous (see Table 1) to a traditional Köhler theory [Köhler, 1936; Laaksonen et al., 1998] which describes the nucleation of cloud drops on water soluble aerosol nuclei. However, in contrast to the traditional Köhler theory, the Nano-Köhler theory describes a thermodynamic equilibrium between a nanometer-size cluster, water and an organic compound that is fully soluble in water, i.e., it does not form a separate solid phase but is totally dissolved into

Table 1. Primary Differences Between the Traditional Köhler Theory [Köhler, 1936; Laaksonen et al., 1998] and the Nano-Köhler Theory $^{\mathrm{a}}$

\begin{tabular}{lll}
\hline \multicolumn{1}{c}{ Theory } & \multicolumn{1}{c}{ Binary Köhler } & Nano-Köhler \\
\hline Activating particles & Cloud condensation nuclei & Inorganic clusters \\
$\quad$ Identity & $>50 \mathrm{~nm}$ & $1-3 \mathrm{~nm}$ \\
$\quad$ Size (diameter) & water & soluble organic compound \\
Activating vapor & $10^{16}-10^{17}$ molecules cm & $10^{6}-10^{8}$ molecules cm ${ }^{-3}$ \\
Identity & $<1.01$ & not limited \\
Gaseous concentration & $C S$, air cooling rate, fluctuations in cooling rate & $C S, Q, P_{0}$, fluctuations in $Q, C S$, and $P_{0}$ \\
Saturation ratio $(S)$ & & \\
Factors influencing $S$ & e.g., $\mathrm{HNO}_{3}, \mathrm{HCl}, \mathrm{NH}_{3}$ & water \\
Secondary vapor & $10^{9}-10^{11} \mathrm{molecules} \mathrm{cm}^{-3}$ & $10^{16}-10^{17} \mathrm{molecules} \mathrm{cm}^{-3}$ \\
Identity &
\end{tabular}

${ }^{\text {a }}$ Here $Q$ is the production rate of condensing vapour, $P_{0}$ is its saturation pressure and $C S$ is the condensation sink. 
the solution. Furthermore, organic and inorganic compounds present together in growing clusters form a single aqueous solution. It is also assumed that gaseous sulphuric acid condenses irreversibly into clusters along with ammonia so that a molar ratio of $1: 1$ is maintained between the concentrations of these two compounds in the solution. This ratio corresponds to ammonium bisulphate and is consistent with the calculated composition of clusters that are formed from ternary sulphuric acid-water-ammonia nucleation [Kulmala et al., 2000]. In practice, these assumptions lead to aqueous-phase concentrations of the organic compound ranging from $<0.1 \mathrm{M}$ in clusters having a diameter $<2 \mathrm{~nm}$ to around $5 \mathrm{M}$ in newly-formed particles with a diameter $>10 \mathrm{~nm}$. These values are in agreement with observed aqueous-phase concentrations of atmospherically relevant organic compounds [Saxena and Hildemann, 1997].

[8] The thermodynamic phase equilibrium for water (wat) and water-soluble organic vapor (os) are determined by the following equations [Laaksonen et al., 1998]:

$$
\begin{gathered}
S_{o s}=x_{o s} \times \gamma_{o s} \times \exp \left(\frac{a_{o s}}{d_{c}}\right), \\
S_{\text {wat }}=x_{\text {wat }} \times \gamma_{\text {wat }} \times \exp \left(\frac{a_{\text {wat }}}{d_{c}}\right) .
\end{gathered}
$$

Here the parameter $S_{i}$ is the equilibrium saturation ratio of the compound $i, x_{i}$ is its mole fraction in the solution, $\gamma_{i}$ is its activity coefficient, $a_{i}$ corresponds to Kelvin term and $d_{c}$ is the cluster diameter. The Kelvin term is given as follows:

$$
a_{i}=\frac{4 \times \sigma \times v_{i}}{R \times T},
$$

where $\sigma$ is the surface tension, $v_{i}$ is the molar volume of the compound $i, R$ is the ideal gas constant and $T$ is the temperature.

[9] In order to solve the above-presented equations simultaneously, the surface tension and activity coefficients of both water and the organic compound need to be estimated. Here we apply a simplified, yet non-ideal thermodynamic model which can be readily implemented into aerosol dynamical models. We assume that that the multicomponent system behaves as a pseudobinary [Petersen et al., 2001], which permits us to treat solution as if it were consisting of two components only: the first one is the organic compound and the second one ammonium bisulphate in ionic form together with associated water. The pseudobinary activity coefficients are determined using Van Laar equations, and the activity coefficient of water is obtained by multiplying the pseudobinary activity coefficient, $\gamma_{p b}$, by that of water in a pure water-ammonium bisulphate solution [Tang and Munkelwitz, 1994]. Accordingly, the activity coefficients $\gamma_{o s}$ and $\gamma_{\text {wat }}$ are calculated using the following equations:

$$
\begin{gathered}
\gamma_{o s}=\exp \frac{a \times b}{R T\left(1+\frac{b \times x_{o s}}{x_{p b}}\right)^{2}}, \\
\gamma_{p b}=\exp \frac{a x_{p b}}{R T\left(1+\frac{x_{p b}}{b \times x_{o s}}\right)^{2}}, \\
\gamma_{\text {wat }}=\gamma_{p b}\left(1-0.305 w-2.94 \times 10^{-1} w^{2}-4.43 \times 10^{-1} w^{3}\right) / x_{\text {wat }} .
\end{gathered}
$$

Here $a$ and $b$ are van Laar coefficients, $x_{p b}$ the mole fraction of the pseudobinary compound, $x_{p b}=1-x_{o s}$, and $w$ and $x_{\text {wat }}$ are the weight fraction of ammonium bisulphate and the mole fraction of water, respectively, in a binary waterammonium bisulphate solution: $w=m_{a} n_{a} /\left(m_{a} n_{a}+m_{w a t} n_{\text {wat }}\right)$, and $x_{\text {wat }}=n_{\text {wat }} /\left(n_{\text {wat }}+2 n_{a}\right)$, where $m_{a}$ and $m_{\text {wat }}$ are the molecular weight of ammonium bisulphate and water, respectively, and $n_{a}$ and $n_{w a t}$ are the numbers of moles of these compounds in the solution, respectively.

[10] For the surface tension we apply an equation that has been used to fit surface tensions of aqueous carboxylic acid solutions [Alvarez et al., 1997]:

$$
\sigma=\sigma_{w b}\left(\sigma_{w b}-\sigma_{o s}\right)\left[1+\frac{c\left(1-x_{o s}\right)}{1-d\left(1-x_{o s}\right)}\right] x_{o s},
$$

where $\sigma_{w b}$ and $\sigma_{o s}$ are the surface tensions of waterammonium bisulphate solution (International Critical Tables of Numerical Data, Physics, Chemistry and Technology, National Research Council of the United States of America, New York, 1926-1933) and the organic compound, respectively, and $c$ and $d$ are free parameters.

[11] To complete the thermodynamic equations, the volumetric properties of the ternary solutions composed of water, ammonium bisulphate, and the organic compound, have to be specified. For simplicity, we approximate the partial molar volumes by the molar volumes of the pure compounds, which are $v_{\text {wat }}, v_{a}$, and $v_{o s}$, respectively. Furthermore, the organic compound is assumed to be a surfactant, i.e., condensed organic matter is partitioned between the bulk solution and surface so that the equation resulting from a sum of Gibbs-Duhem equation and Gibbs adsorption isotherm holds [Laaksonen, 1993].

[12] The equations (3) and (4) describing the thermodynamics of the ternary solutions contain six free parameters that need to be fixed, namely $a, b, c, d, \sigma_{o s}$ and $v_{o s}$. To narrow down the parameter space, we utilize data on hygroscopic properties of $10 \mathrm{~nm}$ particles measured at continental forest site [Hämeri and Väkevä, 2000]. Hämeri and Väkevä measured growth factors mostly at $90 \% \mathrm{RH}$, and the maximum median growth factors were observed to be $\sim 1.28$. They also made two scans of growth factors at relative humidities between $71-90 \%$. Both of these series were measured during the same aerosol formation event so that the first scan was made between noon and $2 \mathrm{pm}$, and the second scan between $3 \mathrm{pm}$ and $5 \mathrm{pm}$. Furthermore, the measured growth factors of the first series were somewhat larger than those of the second series, which was presumably caused by a larger fraction of ammonium bisulphate present in the particles. Hämeri et al. [2001] determined socalled soluble mass fractions of the particles from the hygroscopic growth data, assuming that the only water soluble compound in the particles is ammonium sulphate. The soluble mass fraction determined in this manner, corresponding to the growth factor of 1.28 , was roughly $65 \%$. On the basis of measured growth rates of newlyformed particles and typical gas-phase sulphuric acid concentrations at the measurement site, it is obvious that the $10 \mathrm{~nm}$ particles contain a clearly lower percentage of sulphate, roughly $20-30 \%$.

[13] In practice, the fitting of the free parameters was done as follows: we assumed that the composition of the dry 
Table 2. Values of the Fitted Thermodynamic Parameters in Equations (3) and (4)

\begin{tabular}{cc}
\hline Thermodynamic Parameter & Value \\
\hline $\mathrm{a}$ & -190 \\
$\mathrm{~b}$ & 100 \\
$\mathrm{c}$ & 0.3 \\
$\mathrm{~d}$ & 0.8 \\
$\sigma_{o s}$ & $0.02 \mathrm{~N} / \mathrm{m}$ \\
$v_{o s}$ & $135.5 \mathrm{~cm}^{3} / \mathrm{mol}$ \\
\hline
\end{tabular}

$10 \mathrm{~nm}$ particles corresponding to the maximum median growth factor of 1.28 was $30 \%$ by volume of ammonium bisulphate and $70 \%$ of the organic compound. We then fitted the free thermodynamic parameters in such a way that the measured growth factor was reproduced to a good accuracy (with the final set of thermodynamic parameters, the calculated growth factor corresponding to the 30/70 composition is 1.281 at $90 \% \mathrm{RH})$. In the second stage of the procedure we increased the organic fraction of the dry $10 \mathrm{~nm}$ particles up to $80 \%$, and checked whether the growth factor scans can be reasonably reproduced. The results of the fitting procedures are given in Tables 2 and 3 . Table 2 gives the values of the fitted thermodynamic parameters, and Table 3 shows a comparison of the measured growth factor series and those calculated using the parameters presented in Table 2. As seen, the agreement is quite reasonable.

[14] The set of parameters shown in Table 2 is non-unique in the sense that there exist other parameter sets that would have reproduced the measured growth factors equally well or even better. Furthermore, the assumed ratio of ammonium bisulphate to organic compound in the dry particles affect the values of the parameters. However, it should be noted that after the values of $v_{o s}$ and the surface tension parameters had been fixed, the intervals within which the other parameters had to be chosen in order to reproduce the hygroscopic growth were quite narrow. Therefore the parameter set shown in Table 2 is largely a result of choosing reasonable compromise values for molecular volume of the organic species and for the surface tension parameters, and then performing finetuning with the other parameters. For sensitivity test purposes, we developed alternative thermodynamic parameter sets by assuming variable ammonium bisulphate volume fractions in the range of $20-40 \%$ for the $10 \mathrm{~nm}$ particles with growth factor of 1.28 , and tuning the $v_{o s}$ values so that the hygroscopic growth data were reasonably reproduced. The sensitivity tests are described in the next section.

[15] The resultant equilibrium curves for the organic species condensing onto salt-water nuclei, $1.5,1.7 \mathrm{~nm}$ and $2 \mathrm{~nm}$ in diameter, are illustrated in Figure 1. It is readily seen that equilibrium conditions occur at 3 to 4 orders of magnitude lower saturation ratios than that required for a pure organic drop. In essence, the clusters behave as nuclei for organic aerosol nucleation in a similar manner that aerosols behave as nuclei for cloud droplet nucleation. And in like manner, the larger the nucleus size, the lower the supersaturation required for activation. For example, a stable cluster with initial size of $1.5 \mathrm{~nm}$ requires a saturation ratio of $\sim 100$ for activation, above which the cluster will spontaneously grow into an aerosol particle, while for an initial stable cluster size of $2.2 \mathrm{~nm}$, activation occurs at a saturation ratio of $\sim 15$. Additional calculations (not illustrated by a figure) were conducted to investigate the sensitivity of the activation size to the saturation ratio. These calculations revealed that in a saturation ratio range of unity to 1000 the cluster activation diameter varies from $\sim 5 \mathrm{~nm}$ to $1.3 \mathrm{~nm}$. In comparison, the present nucleation theories predict that the size of thermodynamically stable clusters resulting from nucleation of water, ammonia and sulphuric acid is $\sim 1 \mathrm{~nm}$ in diameter [Kulmala et al., 2000].

[16] As mentioned previously, if the clusters are not activated soon enough, they are scavenged by the preexisting aerosol. This effect is best illustrated by examining the e-folding lifetime (= coagulation rate $^{-1}$ ) of particles as a function of size, also shown in Figure 1. Compared to a $1 \mathrm{~nm}$ particle, a particle of $6 \mathrm{~nm}$ is 20 times more likely to survive. As the particle size increase further to $15 \mathrm{~nm}$, the e-folding lifetime is increased to 100 times that of a $1 \mathrm{~nm}$ particle. In practice, $1 \mathrm{~nm}$ particles cannot survive since their growth rate without activation is too low to overcome the coagulation sink.

\section{Aerosol Dynamics Simulations}

[17] The impact of the nano-particle equilibrium theory must be examined in terms of aerosol dynamics in order to predict the yield of aerosol particles as a function of organic vapor density. To this end, we constructed a sectional aerosol dynamics box model that accounts for nucleation, coagulation, and condensation of vapors, gas-phase processes producing organic condensable vapors and coupled nano-particle thermodynamics. Sulphuric acid vapor is produced by the oxidation of $\mathrm{SO}_{2}$ by $\mathrm{OH}$, following a diurnal cycle and leading to a maximum gas-phase concentration of $5 \times 10^{6} \mathrm{~cm}^{-3}$. For simplicity, the organic production rate is kept constant during the model run. The pre-existing aerosol size distribution comprises two lognormal modes corresponding to the Aitken and Accumulation modes spanning the size range $0.01-1 \mu \mathrm{m}$ and split into 40 size classes. The time evolution of both clusters and nucleation mode classes is split into 100 moving size classes. The condensation sink, typical for a continental boundary layer [Dal Maso et al., 2002], is initially $0.002 \mathrm{~s}^{-1}$. Nucleation rate is fixed at $100 \mathrm{~cm}^{-3} \mathrm{~s}^{-1}$ resulting in a pseudo-constant reservoir of thermodynamically stable clusters of between $60,000-100,000 \mathrm{~cm}^{-3}$. Meteorological

Table 3. A Comparison of the Hygroscopic Growth Factors (GF) Measured by Hämeri and Väkevä [2001] With Those Calculated Using Equations (1)-(4) at Different Relative Humidities ${ }^{\mathrm{a}}$

\begin{tabular}{lcc}
\hline $\mathrm{RH}$ & GF(Measured) & GF(Calculated) \\
\hline & Series 1 & \\
$71 \%$ & 1.14 & 1.135 \\
$80 \%$ & 1.18 & 1.179 \\
$90 \%$ & 1.25 & 1.262 \\
& Series 2 & \\
$71 \%$ & 1.12 & 1.128 \\
$84 \%$ & 1.19 & 1.196 \\
$90 \%$ & $1.23-1.26$ & 1.250 \\
\hline
\end{tabular}

${ }^{\mathrm{a}}$ In the first series, the dry particles consist of $25 \%$ of ammonium bisulphate and $75 \%$ of an organic compound. In the second series, the respective mass fractions are 22 and $78 \%$. 


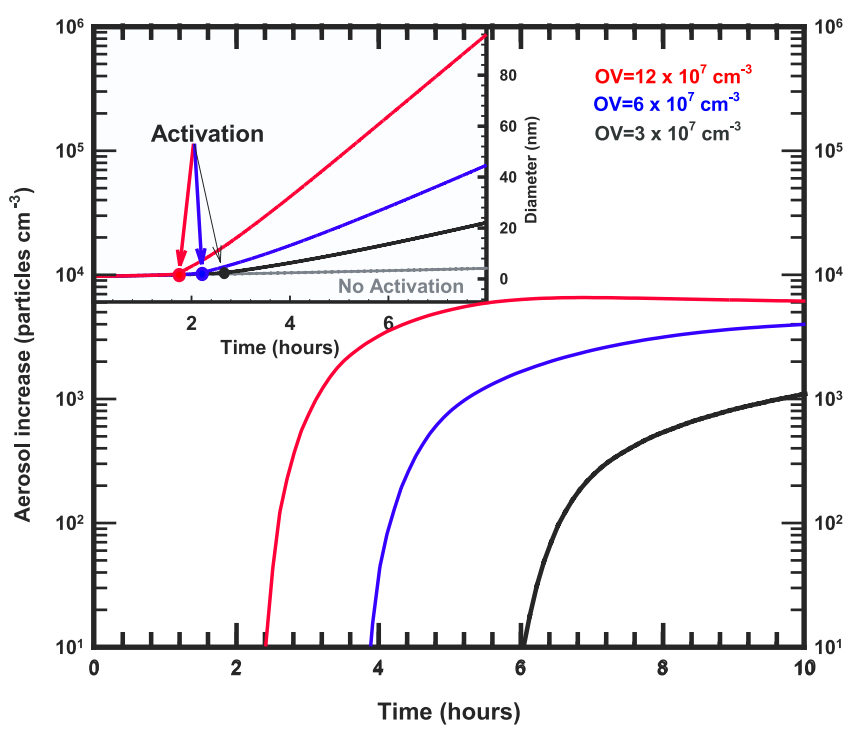

Figure 2. Growth of sulphate clusters and resulting nanoparticles as a function of time for organic vapor (OV) concentrations 3, 6 and $12 \times 10^{7}$ molecules $\mathrm{cm}^{-3}$ (inset). The point of activation is highlighted by the dot on the curve. Also shown is the time evolution of the cluster size without nano-particle equilibrium theory incorporated into the dynamics model. The time evolution of the increase in concentration for particle sizes greater than $15 \mathrm{~nm}$ is shown in the main plot for the three organic vapor scenarios.

parameters, which are temperature and relative humidity, were set equal to $288 \mathrm{~K}$ and $80 \%$, respectively. Finally, simulations were started at 8 AM local time.

[18] Numerical simulations were conducted using three different organic production rates corresponding to gas-phase concentrations of 3,6 and $12 \times 10^{7}$ molecules $\mathrm{cm}^{-3}$, respectively. The dynamic evolution and increase in particle concentration is illustrated in Figure 2. In the inset figure, it can be seen that without the new activation theory, minimal growth of the clusters is observed even after 8 hours; however, when activation of the clusters by the organic vapor is included, for an organic vapor concentration of $3 \times 10^{7} \mathrm{~cm}^{-3}$, a rapid increase in growth is initiated after $\sim 2.5$ hours, leading to a particle size of $20 \mathrm{~nm}$ after 8 hours. As the concentration of the organic vapor is increased, the activation time is reduced and the growth rate is increased further. For the higher organic vapor scenario of $12 \times 10^{7} \mathrm{~cm}^{-3}$, activation is initiated after $\sim 1.7$ hours, leading to a particle size of $90 \mathrm{~nm}$ after 8 hours.

[19] In terms of increases in total particle concentration, we choose to present the increase in particle concentration at sizes larger than $15 \mathrm{~nm}$ since particles above these sizes posses a very high probability of surviving and growing into sizes where they directly scatter solar radiation $(d>100 \mathrm{~nm})$ and behave as cloud condensation nuclei. For the lower organic vapor concentration scenario $\left(3 \times 10^{7} \mathrm{~cm}^{-3}\right)$ and increase in aerosol concentration of $\sim 1000 \mathrm{~cm}^{-3}$ is achieved after 10 hours while doubling the organic vapor concentration to $6 \times 10^{7} \mathrm{~cm}^{-3}$ leads to an increase of $\sim 4000 \mathrm{~cm}^{-3}$ in the concentration. Increasing the vapor concentration further to $12 \times 10^{7} \mathrm{~cm}^{-3}$ leads to an increase in the aerosol concentration to $\sim 6000 \mathrm{~cm}^{-3}$ over a period of 10 hours. In summary, for moderately low concentrations of organic vapors, a $100 \%$ increase in the vapor concentration results in a $400 \%$ increase in the number of particles having a diameter $>15 \mathrm{~nm}$ over a period of 10 hours while at moderately high vapor concentrations $100 \%$ increase leads to an additional $50 \%$ increase in the particle number concentration at the discussed size range. The maximum number concentration of secondary particles having a diameter above $3 \mathrm{~nm}$ is around 2300, 4500, and $6500 \mathrm{~cm}^{-3}$, respectively, in these three model runs.

[20] The model simulations illustrate that prior to the activation, the cluster growth is driven by $\mathrm{H}_{2} \mathrm{SO}_{4}$ condensation. This leads to a dual step process, one involving sulphuric acid and organic vapor condensation growth of the nuclei to the threshold size and the other involving organic condensation during activation. Sensitivities studies indicate that, for organic aerosol formation to occur, two requirements must be met: (1) sulphuric acid concentrations must be of the order of $2.5 \times 10^{6}$ molecules or higher otherwise, the clusters are scavenged before they can be activated; and (2) the condensable organic vapor concentration must be greater than $\sim 10^{7}$ molecules $\mathrm{cm}^{-3}$. Higher concentrations of sulphuric acid will result in activation at lower organic vapor concentrations.

[21] To study the sensitivity of the aerosol dynamics to the thermodynamic model chosen and the assumption concerning the composition of the $10 \mathrm{~nm}$ particles measured by Hämeri et al. [2001] and Hämeri and Väkevä [2000], we refitted the thermodynamic parameters by assuming that the volume fraction of ammonium bisulphate in the $10 \mathrm{~nm}$ particles with growth factor of 1.28 is either $40 \%$ or $20 \%$. In the former case it was sufficient to grow the molar volume of the organic molecule by a factor of 1.5 and in the latter case to shrink it by a factor of 0.75 to be able to reproduce the hygroscopic growth data shown in Table 3. These changes led to increase of the Köhler curve maxima for the $1.5 \mathrm{~nm}$ particles of Figure 1 roughly by a factor of 100 in the former case, and to a decrease by a factor of roughly 10 in the latter case. The aerosol dynamics simulations were repeated by using the altered organic molecular volumes together with altered organic saturation vapor pressures in order to ensure that the gas phase concentrations of the organic vapor stayed at levels needed to reproduce observed growth rates. Thus, in the first sensitivity test, the volume of the organic molecule was increased by a factor of 1.5 and its saturation vapor pressure was decreased by two orders of magnitude. These changes had minimal effects on the aerosol formation dynamics shown in Figure 2. In the second test, the volume of the organic molecule was decreased by a factor of 0.75 and its saturation vapor pressure increased by one order of magnitude. Compared to the base case, $3 \mathrm{~nm}$ particle formation rates grew maximally by $20 \%$ and the concentrations of newly formed particles increased at maximum by a factor of 1.25 . Thus these tests do not indicate that the aerosol formation dynamics depends very sensitively on the assumed composition of the $10 \mathrm{~nm}$ particles observed by Hämeri et al. $[2000,2001]$ and used in constraining the thermodynamic parameters. It should once again be pointed out, however, that there are other thermodynamic parameter sets that will produce similar hygroscopic behavior for the $10 \mathrm{~nm}$ par- 
ticles. Studies of whether some of these alternative thermodynamics result in strongly modified particle formation dynamics will be left to the future.

\section{Discussion and Conclusions}

[22] The obtained results contain inevitably some uncertainties. One of their major sources consists of the applied thermodynamic model described in section 2. Freshlynucleated clusters comprise of highly concentrated solutions that exhibit strongly non-ideal behavior and owing to the extremely small size of these clusters, the magnitude of the Kelvin effect depends strongly on the cluster surface tension and molecular volume of condensing molecule. This highlights the need to predict accurately the cluster surface tension and activity coefficients which can be only done by using a sufficiently sophisticated thermodynamic framework. While more comprehensive models than the one applied here have been developed [e.g., Clegg et al., 2001; Ming and Russell, 2002], their use requires thermodynamic data that is not presently available. Furthermore, use of such models in aerosol dynamic codes would be computationally very expensive. The strength of the chosen approach lies in its computational efficiency and the ability to extract the required parameters from the HTDMA data.

[23] The choice of the required thermodynamic parameters contains also some uncertainties. Because actual organic compounds involved in atmospheric particle formation are not known at present and the knowledge concerning the physico-chemical properties of organic compounds identified in the atmosphere is sparse, several assumptions must be made on the properties of condensing organic compound. For example, it was assumed that the organic compound was water-soluble which is consistent with the finding that organic nano-particles formed in a boreal forest have high hygroscopic growth factors [Hämeri et al., 2001]. However, in some different atmospheric environment organic vapors driving particle formation might be slightly-soluble or totally water-insoluble. Such compounds cannot be included in the applied model since it does not account for a possible phase separation taking place in growing clusters or particles. It was also assumed that the condensing organic vapor does not participate in any heterogeneous reactions that might increase compound uptake. These remarks illustrate difficulties in quantifying errors contained by the approach and the need to obtain more physico-chemical data on atmospheric organic compounds.

[24] While containing some uncertainties that can be resolved in the future, the new theory underpins the essential processes involved in formation of organic particles from freshly-nucleated inorganic clusters and provides a mechanism for more accurate representation of organic aerosol formation processes in global climate prediction models. Furthermore, it also suggests that small increases in the availability or production of organic vapors will lead to large increases in the aerosol population. Such an increase in production of condensable organic vapors could result from increasing oxidant concentrations (e.g., ozone) associated with globally increasing pollution levels. The resultant increase in aerosol concentrations would have a significant impact on the global radiative cooling of aerosols and clouds and therefore global climate change.
[25] Acknowledgments. This work was supported by the European Commission and the Academy of Finland and Maj and Tor Nessling Foundation.

\section{References}

Alvarez, E., G. Vazquez, M. Sanchez-Vilas, B. Sanjurjo, and J. M. Navaza (1997), Surface tension of organic acids + water binary mixtures from $20^{\circ} \mathrm{C}$ to $50^{\circ} \mathrm{C}, \mathrm{J}$. Chem. Eng. Data, 42, 957-960.

Anttila, T., and V.-M. Kerminen (2003), Condensational growth of atmospheric nuclei by organic vapours, J. Aerosol Sci., 34, 41-61.

Bonn, B., and G. K. Moortgat (2003), Sesquiterpene ozonolysis: Origin of atmospheric new particle formation from biogenic hydrocarbons, Geophys. Res. Lett., 30(11), 1585, doi:10.1029/2003GL017000.

Charlson, R. J., J. E. Lovelock, M. O. Andreae, and S. G. Warren (1987), Oceanic phytoplankton, atmospheric sulphur, cloud albedo and climate, Nature, 326, 655-661.

Charlson, R. J., S. E. Schwartz, J. M. Hales, R. D. Cess, J. A. Coakley, J. E. Hansen, and D. J. Hofmann (1992), Climate forcing by anthropogenic aerosols, Science, 255, 423-430.

Clegg, S. L., J. H. Seinfeld, and P. Brimblecombe (2001), Thermodynamic modelling of aqueous aerosols containing electrolytes and dissolved organic compounds, J. Aerosol Sci., 32, 713-738.

Dal Maso, M., M. Kulmala, J. Mäkelä, P. Aalto, and C. D. O’Dowd (2002), Condensation and coagulation sinks and the formation of nucleation mode particles in coastal and boreal forest boundary layers, J. Geophys. Res., 107(D19), 8097, doi:10.1029/2001JD001053.

Hämeri, K., and M. Väkevä (2000), Ultrafine aerosol particle hygroscopicity and volatility in boreal forest, Rep. Ser. Aerosol Sci., 47, 47-59.

Hämeri, K., M. Väkevä, P. P. Aalto, M. Kulmala, E. Swietlicki, J. Zhou, W. Seidl, E. Becker, and C. D. O'Dowd (2001), Hygroscopic and CCN properties of aerosol particles in boreal forest, Tellus, 53B, 359-379.

Houghton, J. T., Y. Ding, D. J. Griggs, M. Noguer, P. J. van der Linden, X. Dai, K. Maskell, and C. A. Johnson (Eds.) (2001), Climate Change 2001: The Scientific Basis. Contribution of Working Group I to the Third Assessment Report of the Intergovernmental Panel on Climate Change, Cambridge Univ. Press, New York.

Jang, M., N. M. Czosche, S. Lee, and R. M. Kamens (2002), Heterogeneous atmospheric aerosol production by acid-catalyzed particle-phase reactions, Science, 298, 814-817.

Kavouras, I. G., and E. G. Stephanou (2002), Direct evidence of atmospheric secondary organic aerosol formation in forest atmosphere through heteromolecular nucleation, Environ. Sci. Technol., 36, 5083-5091.

Kavouras, I. G., N. Mihalopoulos, and E. G. Stephanou (1998), Formation of atmospheric particles from organic acids produced by forests, Nature, $395,683-686$.

Kerminen, V.-M. (1999), Roles of $\mathrm{SO}_{2}$ and secondary organics in the growth of nanometer particles in the lower atmosphere, J. Aerosol Sci., 30, 1069-1078.

Kerminen, V.-M., A. Virkkula, R. Hillamo, A. S. Wexler, and M. Kulmala (2000), Secondary organics and atmospheric cloud condensation nuclei production, J. Geophys. Res., 105, 9255-9264.

Köhler, H. (1936), The nucleus in the growth of hygroscopic droplets, Trans. Faraday Soc., 32, 1152-1161.

Kulmala, M., A. Toivonen, J. M. Mäkelä, and A. Laaksonen (1998), Analysis of the growth of nucleation mode observed in Boreal forest, Tellus, $50 B, 449-462$.

Kulmala, M., L. Pirjola, and J. M. Mäkelä (2000), Stable sulphate clusters as a source of new atmospheric particles, Nature, 404, 66-69.

Kulmala, M., et al. (2001), Overview of the international project on Biogenic aerosol formation in the boreal forest (BIOFOR), Tellus, 53B, 324343 .

Laaksonen, A. (1993), The composition size dependence of aerosols created by disperdion of surfactant solutions, J. Colloid Interface Sci., 159, $517-519$.

Laaksonen, A., P. Korhonen, M. Kulmala, and R. J. Charlson (1998), Modification of the Köhler equation to include soluble trace gases and slightly soluble substances, J. Atmos. Sci., 55, 853-862.

Leaitch, W. R., J. W. Bottenheim, T. A. Biesenthal, S.-M. Li, P. S. K. Liu, K. Asalian, H. Dryfhout-Clark, F. Hopper, and F. Brechtel (1999), A case study of gas-to-particle conversion in an eastern Canadian forest, J. Geophys. Res., 104, 8095-8111.

Marti, J. J., R. J. Weber, P. H. McMurry, F. Eisele, D. Tanner, and A. Jefferson (1997), New particle formation at a remote continental site: Assessing the contributions of $\mathrm{SO}_{2}$ and organic precursors, J. Geophys. Res., 102, 6331-6339.

Ming, Y., and L. M. Russell (2002), Thermodynamic equilibrium of organicelectrolyte mixtures in aerosol particles, AIChE J., 48, 1331-1348.

Noziére, B., and D. D. Riemer (2003), The chemical processing of gasphase carbonyl compounds by sulphuric acid aerosols: 2, 4-pentanedione, Atmos. Env., 37, 841-851. 
O’Dowd, C. D., J. L. Jimenez, R. Bahreini, R. C. Flagan, J. H. Seinfeld, L. Pirjola, M. Kulmala, S. G. Jennings, and T. Hoffmann (2002a), Marine particle formation from biogenic iodine emissions, Nature, 417, 632636.

O'Dowd, C. D., et al. (2002b), A dedicated study of new particle formation and fate in the coastal environment (PARFORCE): Overview of objectives and initial achievements, J. Geophys. Res., 107(D19), 8108, doi:10.1029/2000JD000555.

O’Dowd, C. D., P. Aalto, K. Hämeri, M. Kulmala, and T. Hoffmann (2002c), Atmospheric particles from organic vapours, Nature, 416, 497-498.

Petersen, D., R. Ortner, A. Vrtala, P. E. Wagner, M. Kulmala, and A. Laaksonen (2001) Soluble-insoluble transition in binary heterogeneous nucleation, Phys. Rev. Lett., 87, doi:10.1103/PhysRevLett.87.225703.

Saxena, P., and L. M. Hildemann (1997), Water absorption by organics: Survey of laboratory evidence and evaluation of UNIFAC for estimating water activity, Environ. Sci. Technol., 31, 3318-3324.

Seinfeld, J. H., and S. N. Pandis (1998), Atmospheric Chemistry and Physics, From Air Pollution to Climate Change, John Wiley, Hoboken, N. J.

Tang, I. N., and H. R. Munkelwitz (1994), Water activities, densities, and refractive indices of aqueous sulfates and sodium nitrate droplets of atmospheric importance, J. Geophys. Res., 99, 18,801-18,808.
Tobias, H. J., and P. J. Ziemann (2000), Thermal desorption mass spectrometric analysis of organic aerosol formed from reactions of 1-Tetradecene and $\mathrm{O}_{3}$ in the presence of alcohols and carboxylic acids, Environ. Sci. Technol., 34, 2105-2115.

Zhang, K. M., and A. S. Wexler (2002), A hypothesis for growth of fresh atmospheric nuclei, J. Geophys. Res., 107(D21), 4577, doi:10.1029/ 2002JD002180.

T. Anttila and M. Kulmala, Department of Physical Sciences, University of Helsinki, P.O. Box 64, FIN-00014 University of Helsinki, Helsinki, Finland.

V.-M. Kerminen, Air Quality Research, Finnish Meteorological Institute, Sahaajankatu 20E, FIN-00880 Helsinki, Finland.

A. Laaksonen, Department of Applied Physics, University of Kuopio, P.O. Box 1627, FIN-70211 Kuopio, Finland.

C. D. O'Dowd, Department of Experimental Physics and Environmental Change Institute, National University of Ireland, Galway, University Road, Galway, Ireland. 